Gut, 1978, 19, 1121-1124

\title{
Lower oesophageal sphincter response to intravenous infusions of pentagastrin in normal subjects, antrectomised and achalasic patients ${ }^{1}$
}

\author{
E. CORAZZIARI, C. POZZESSERE, S. DANI, F. ANZINI, AND A. TORSOLI \\ From the Cattedra di Gastroenterologia, Clinica Medica II, University of Rome, Rome, Italy
}

SUMMARY Lower oesophageal sphincter response to infusion of graded doses (0.003-0.050 $\mu \mathrm{g}$ $\mathrm{kg}^{-1} \mathrm{~min}^{-1}$ ) of pentagastrin was evaluated in four antrectomised patients as well as in six healthy subjects and seven achalasic patients in whom inhibition of antral gastrin release was maintained by continuous acidification $(\mathrm{HCl} 0 \cdot 1 \mathrm{~N})$ and aspiration of gastric antrum. In normal subjects and in antrectomised patients doses of pentagastrin required for half-maximal gastric acid secretion $\left(0.012 \mu \mathrm{g} \mathrm{kg}^{-1} \mathrm{~min}^{-1}\right)$ produced statistically significant increases of LES pressure. In achalasic patients, the infusion of pentagastrin did not affect LES pressure. These data seem to indicate that gastrin plays, at least in some degree, a physiological role in the regulation of LES tone. Insensitivity of LES to pentagastrin in achalasia suggests that the raised sphincter pressure in this disorder can not be attributed to gastrin.

Gastrin and its analogue pentagastrin (PG) have been shown to increase lower oesophageal sphincter (LES) pressure (Giles et al., 1969; Castell and Harris, 1970). This effect has been reported to be enhanced in patients with achalasia (Cohen et al., 1971). Other studies, however, did not confirm these data (Farrell et al., 1974; Sturdevant and Kun, 1974; Goyal and McGuigan, 1976; Walker et al., 1975), and the role of the hormone in maintaining LES tone has yet to be determined.

In previous investigations little consideration has been given to possible variations in endogenous serum gastrin levels during basal and stimulation periods. It might well be that variable endogenous serum gastrin levels interact at receptor sites with exogenous gastrin or pentagastrin, thus altering the resulting data. The aim of the present study was to evaluate the LES pressure response to graded doses of PG in subjects during maximal inhibition of antral gastrin release. Normal subjects and achalasic patients in whom the antral mucosa was continuously bathed with $\mathrm{HCl} 0 \cdot 1 \mathrm{~N}$ solution (Walsh et al., 1975), as well as antrectomised patients, were investigated.

${ }^{1}$ This work was presented in part to the American Gastroenterological Association, May 1977, Toronto, Canada.

Received for publication 8 June 1978

\section{Methods}

Six normal volunteers (four males and two females), four male patients, previously operated upon for duodenal ulcer with antrectomy and gastrojejunal anastomosis, and seven achalasic patients (four males and three females), were investigated. Diagnosis of achalasia was made on the basis of radiological, endoscopic, and manometric findings. None of the normal and antrectomised subjects had symptoms related to the gastrointestinal tract and particularly clinical, radiological, and $\mathrm{pH}$-manometric evidence of gastro-oesophageal reflux was lacking; none was taking drugs of any kind.

Three water-filled, polyvinyl catheters, $1 \mathrm{~mm}$ internal diameter, were used to transmit intraluminal pressures to Elema-Schönander external transducers. Manometric variations were then recorded on a multichannel Hellige polygraph. The catheters had side openings, $1.2 \mathrm{~mm}$ in diameter, arranged to measure intraluminal pressures at three points, $5 \mathrm{~cm}$ apart. The pressure recording tubes were perfused with distilled water at a constant rate of $0.750 \mathrm{ml} / \mathrm{min}$ using a Braun syringe pump.

Constant $\mathrm{HCl} 0 \cdot 1 \mathrm{~N}$ infusion $(6 \mathrm{ml} / \mathrm{min})$ and aspiration was done through two additional catheters $(1.8 \mathrm{~mm}$ internal diameter). These had multiple perforations over the $8 \mathrm{~cm}$ distal segments and were positioned in the gastric antrum under fluoroscopic 
control. The five polyvinyl catheters were joined into a single unit with an external diameter of $6.2 \mathrm{~mm}$. The middle recording orifice was $16 \mathrm{~cm}$ proximal to the distal tips of the multiperforated catheters.

All subjects were studied in the supine position after overnight fasting. The recording assembly was positioned with all the orifices in the stomach. After a 15 minute rest-period LES pressure was measured by a $0.5 \mathrm{~cm}$ interval pull-through of the catheters. The assembly was then positioned again in the stomach and during a second pull-through the catheters were anchored so that the middle recording orifice recorded from the highest pressure point in the lower oesophageal sphincter. Pressures were simultaneously recorded from the oesophagus and the stomach. LES pressure was continuously recorded during a 10 minute intravenous saline infusion and for five successive 10 minute periods of graded doses of intravenous pentagastrin infusion (0.003; $\left.0.006 ; 0.012 ; 0.025 ; 0.050 \mu \mathrm{g} \mathrm{kg}^{-1} \mathrm{~min}^{-1}\right)$. In the normal subjects and in the achalasic patients, after preliminary gastricemptying, continuous acidification of the gastric antrum and continuous aspiration of gastric contents was performed for 30 minutes before, and for the duration of, the intravenous infusion period.

LES pressure was recorded as $\mathrm{cm}_{2} \mathrm{O}$ with the mean gastric fundic pressure as the zero reference. The middle inspiratory pressure was reported as the sphincter pressure. LES pressure was measured at one minute intervals or, if the subject happened to swallow, 20 seconds after the end of sphincter inhibition.

Manometric tracings were coded and evaluated blindly at the end of the entire study. Student's $t$ test analysis of variance (two-way classification), and Duncan's test were used to evaluate data.

\section{Results}

Mean basal LES pressure in normal subjects was $27 \cdot 8 \pm 5 \mathrm{~cm} \mathrm{H}_{2} \mathrm{O} \quad(\mathrm{M} \pm \mathrm{SEM})$ compared with $22.4 \pm 2 \mathrm{~cm} \mathrm{H}_{2} \mathrm{O}$ in the antrectomised patients $(P>0.05)$ and $43.7 \pm 6.2 \mathrm{~cm} \mathrm{H}_{2} \mathrm{O}$ in the patients with achalasia $(P>0 \cdot 05)$. During the first 30 minute period of antral acidification, LES pressure increased to $36.3 \pm 7 \mathrm{~cm} \mathrm{H}_{2} \mathrm{O}$ in normal subjects and decreased to $42.4 \pm 7 \cdot 2 \mathrm{~cm} \mathrm{H}_{2} \mathrm{O}$ in the achalasic patients. Neither change was statistically significant $(P>0.05)$.

In normal subjects, the sphincter pressure progressively increased during graded doses of pentagastrin infusion with significant variation at doses of $0.012 \mu \mathrm{g} \mathrm{kg}^{-1} \mathrm{~min}^{-1} \quad(\mathrm{P}<0.05)$ and of $0.025 \mu \mathrm{g}$ $\mathrm{kg}^{-1} \min ^{-1} \quad(\mathrm{P}<0.01)$ (Fig. 1). In antrectomised patients, LES pressure increased during PG administration to reach $33 \cdot 1 \pm 2 \mathrm{~cm} \mathrm{H}_{2} \mathrm{O}$ with the final

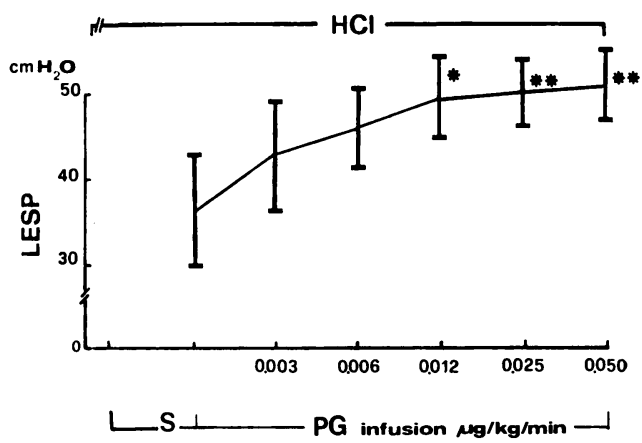

Fig .1 LES pressure values during infusion of saline $(S)$ and graded doses of pentagastrin $(P G)$ in normal subjects. $\mathrm{HCl}$ indicates period of antral acidification. ${ }^{*} \mathrm{P}<0.05 ;{ }^{* *} \mathrm{P}<0.01$.

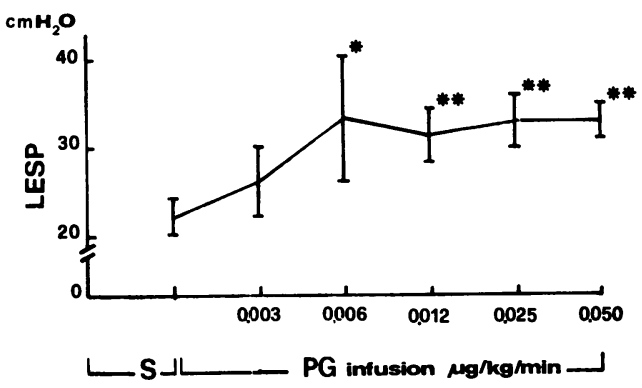

Fig. 2 LES pressure values during infusion of saline $(S)$ and graded doses of pentagastrin $(P G)$ in antrectomised patients. ${ }^{*} \mathrm{P}<0.05 ;{ }^{* *} \mathrm{P}<0.01$.

dose. The LES pressure increment was significantly different at doses of $0.006 \mu \mathrm{g} \mathrm{kg}^{-1} \mathrm{~min}^{-1}(\mathrm{P}<0.05)$ and $0.012 \mu \mathrm{g} \mathrm{kg}^{-1} \min ^{-1}(\mathrm{P}<0.01)$ (Fig. 2). In the patients with achalasia the infusion of graded doses of pentagastrin did not affect the pressure of the lower oesophageal sphincter (Fig. 3).

\section{Discussion}

It has been stated that producing a response with continuous infusion of a polypeptide at a dose calculated to give one-half the maximal response in the target organ represents one of the main criteria to establish the physiological role of a hormone (Grossman, 1977). Walker et al. (1975) reported that there was no statistically significant increase in LES pressure during PG infusion at doses of 0.004-12 $\mu \mathrm{g} \mathrm{kg}^{-1} \mathrm{~h}^{-1}$; however, examination of individual results suggested that PG might be stimulating LES pressure in some subjects and inhibiting it in others. Two further studies (Hogan et al., 1974; Kaye et al., 1976) showed that LES pressure increased during continuous infusion of PG at above maximal (0.04 


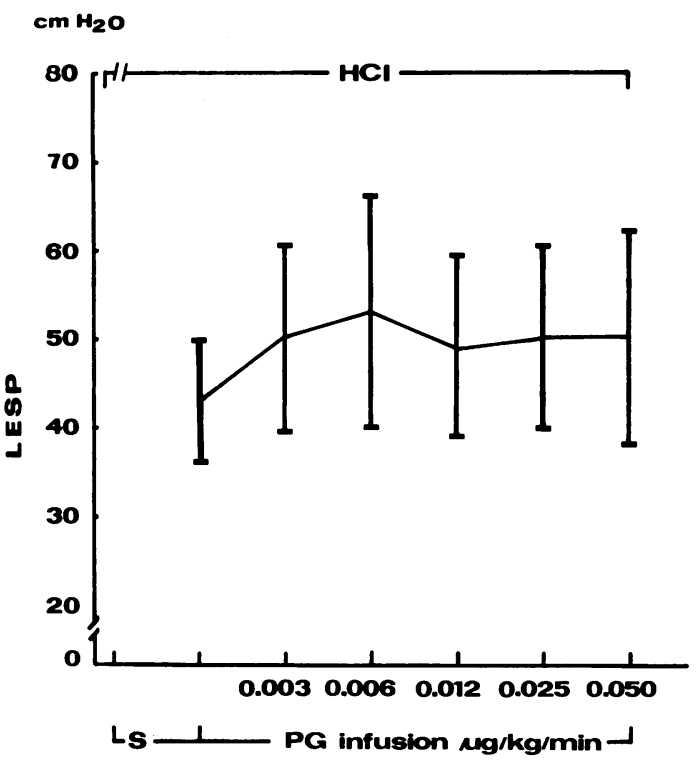

Fig. 3 LES pressure values during infusion of saline $(S)$ and graded doses of pentagastrin $(P G)$ in achalasic patients. $\mathrm{HCl}$ indicates period of antral acidification.

$\left.\mu \mathrm{g} \mathrm{kg}^{-1} \mathrm{~h}^{-1}\right)$ or submaximal $\left(0.9 \mu \mathrm{g} \mathrm{kg}^{-1} \mathrm{~h}^{-1}\right)$ doses for gastric acid secretion in man. In a recent study (Freeland et al., 1976), the continuous infusion of gastrin heptadecapeptide I at doses within the physiological range induced a significant increase in LES pressure. Such different and contrasting results might indicate that endogenous individual factors may interfere with the exogenous stimuli at level of LES. Up until now little relevance has been given to possible interactions between the exogenous polypeptide and analogous hormone acting on the same receptor sites. It is possible that effects of hormonal substances might be difficult to evaluate due to variations of serum gastrin levels in basal conditions and during gastrin or pentagastrin administration, because of the feedback mechanism between acid secretion and antral gastrin release. Moreover, even the measurement of total gastrin immunoreactivity in serum does not correlate with LES pressure possibly because of the different biological actions of various molecular gastrin types (Higgs et al., 1971; Dodds et al., 1974; Morris et al., 1974; Freeland et al., 1976).

Data of the present study show that continuous intravenous PG infusion stimulates LES pressure in normal and antrectomised subjects. Significant increase of LES pressure was obtained with doses of pentagastrin near (Isenberg et al., 1975) or equal to (Multicentre Pilot Study, 1967) those calculated to give one-half the maximal acid secretion in man. In the present study the carboxyl-terminal aminoacid sequence of gastrin stimulated LES pressure during maximal constant inhibition or absence of gastrin release from the gastric antrum; although the data do not exclude the possibility that the various molecular forms of the hormone might differ in their action upon the sphincter, they suggest that gastrin is, at least partly, involved in the regulation of LES tone in physiological conditions. The lower mean peak sphincter pressure during pentagastrin infusion in antrectomised patients as compared with normal subjects, although not statistically significant, suggests that some factor other than gastrin is responsible for lowering the resting sphincter pressure after antrectomy.

An exaggerated LES response to intravenous bolus gastrin administration has been recorded (Cohen $e t$ al., 1971) in achalasia, suggesting that in these patients a gastrin supersensitivity of the LES exists. Data of the present study indicate that continuous intravenous infusion of pentagastrin does not affect LES pressure in achalasia and suggest that gastrin plays no role in the maintenance of the raised sphincter tone in this disorder.

Acidification of the gastric antrum has been reported to inhibit LES pressure in both normal subjects and in achalasic patients and this finding has suggested that sphincter pressure is determined by endogenous gastrin (Cohen et al., 1971). The present study does not confirm these results and indicates that acidification of the antrum does not significantly affect LES pressure in both normal subjects and achalasic patients; unlike the study of Cohen et al., however, in this investigation, continuous aspiration of gastric contents during antral acidification prevented gastric distension.

All the above findings suggest that basal endogenous gastrin does not influence LES pressure, while, more raised serum gastrin levels, as can occur after a meal, might take part in the regulation of LES tone in normal subjects.

This study was supported by CNR grant no. 76.01525 115.3329. The authors wish to thank J. H. Walsh for valuable criticism.

\section{References}

Castell, D. O., and Harris, L. D. (1970). Hormonal control of gastroesophageal-sphincter strength. New England Journal of Medicine, 282, 886-889.

Cohen, S., Lipshutz, W. H., and Hughes, W. (1971). Role of gastrin supersensitivity in the pathogenesis of lower esophageal sphincter hypertension in achalasia. Journal of Clinical Investigation, 50, 1241-1247.

Dodds, W. J., Hogan, W. J., Miller, W. N., Arndorfer, R. C., and Barreras R. F. (1974). Relationship between serum gastrin levels and lower esophageal sphincter pressure in fasting subjects. Gastroenterology, 66, 686. 
Farrell, R. L., Castell, D. O., and McGuigan, J. E. (1974). Measurements and comparisons of lower esophageal sphincter pressures and serum gastrin levels in patients with gastroesophageal reflux. Gastroenterology, 67, 415-422.

Freeland, G. R., Higgs, R. H , Castell, D. O., and McGuigan, J. E. (1976). Lower esophageal sphincter and gastric acid response to intravenous infusions of synthetic human gastrin I heptadecapeptide. Gastroenterology, 71, 570-574.

Giles, G. R., Mason, M. C., Humphries, C., and Clark, C. G. (1969). Action of gastrin on the lower esophageal sphincter in man. Gut, 10, 730-734.

Goyal, R. K., and McGuigan, J. E. (1976). Is gastrin a major determinant of basal lower esophageal sphincter pressure? A double-blind controlled study using high titer gastrin antiserum. Journal of Clinical Investigation, 57, 291-300.

Grossman, M. I. (1977). Physiological effects of gastrointestinal hormones. Federation Proceedings, 36, 1930-1932.

Higgs, R. H., Smyth, R. D., and Castell, D. O. (1971). Gastric alkalinization; effect on lower-esophageal-sphincter pressure and serum gastrin. New England Journal of Medicine, 291, 486-490.

Hogan, W. J., Gardner, J. D., Malloy, R. G., Dodds, W. J., and Arndorfer, R. C. (1974). Comparison of human anal sphincter and lower esophageal sphincter response to enteric hormone administration (Abstract). Gastroenterology, 66, 845 .

Isenberg, J. I., Grossman, M. I., Maxwell, V., and Walsh,
J. H. (1975). Increased sensitivity to stimulation of acid secretion by pentagastrin in duodenal ulcer. Journal of Clinical Investigation, 55, 330-337.

Kaye, M. D., Rein, R., Johnson, W. P., and Showalter, J. P. (1976). Responses of the competent and incompetent lower oesophageal sphincter to pentagastrin and abdominal compression. Gut, 17, 933-939.

Morris, D. W., Schoen, H., Brooks, F. P., and Cohen, S. (1974). Relationship of serum gastrin and lower esophageal sphincter pressure in normals and patients with antrectomy (Abstract). Gastroenterology, 66, 750.

Multicentre Pilot Study (1967). Pentagastrin as a stimulant of maximal gastric acid response in man. Lancet, 1, 291-295.

Sturdevant, R. A. L., and Kun, T. L. (1974). Gastrin and gastroesophageal sphincter incompetence. In Proceedings of the Fourth International Symposium on Gastrointestinal Motility, pp. 125-130. Edited by E. E. Daniel et al. Mitchell Press: Vancouver.

Walker, C. O., Frank, S. A., Manton, J., and Fordtran, J. S. (1975). Effect of continuous infusion of pentagastrin on lower esophageal sphincter pressure and gastric acid secretion in normal subjects. Journal of Clinical Investigation, 56, 218-225.

Walsh, J. H., Richardson, C. T., and Fordtran, J. S. (1975). $\mathrm{PH}$-dependence of acid secretion and gastrin release in normal and ulcer subjects. Journal of Clinical Investigation, 55, $462-468$. 